\title{
THE LEGAL DEFENSE OF RADIO ASTRONOMY
}

\author{
JAMES G. ENNIS, ESQ. \\ Fletcher, Heald \& Hildreth, Washington, DC U.S.A.
}

The purpose of this paper is to describe one program of the National Academy of Sciences' Committee on Radio Frequencies ("CORF"). This program uses legal means to protect radio astronomy frequencies from radio interference.

CORF is composed of eminent scientists from the fields of radio astronomy, space research, remote sensing, meteorology, and wildlife tracking who use radio frequencies in conducting their research. CORF's primary objective is to limit the level of harmful man-made interference in the bands used by these scientists as much as possible.

A few years ago, in the course of attempting to limit harmful man-made interference, CORF concluded that it was not learning about proposed new uses of radio at an early enough stage to be able to provide the Federal Communications Commission (FCC) with timely comments about the effect of these new uses of radio on scientific research. The FCC is the government agency in the U.S. which is responsible for determining what radio services may use which bands and for assigning licenses to entities to provide these radio services.

To remedy this situation, CORF retained legal counsel. The task of the legal counsel was, and is today, to review proposals for radio services which are filed with the FCC and applications for licenses to provide such services, and to identify those which could increase the level of interference in the bands used by radio astronomers and other members of CORF. If the scientists in CORF believe the proposal or application will cause harmful interference to their research, the legal counsel assists CORF in preparing comments on the proposal to the FCC.

Funding for this program was (and is) provided by grants from the National Science Foundation (NSF) and NASA. A large measure of credit for establishing this program must go, among others, to Dr. Vernon L. Pankonin, who was in charge of spectrum management at the NSF at the time the program was established, and to Martin Rothblatt, who at the time the program was established was an attorney in private practice and an amateur radio astronomer and who is one of the speakers at this colloquium. Martin became the first legal counsel for CORF. After he decided to leave private practice to take a position as the President and CEO of Geostar Corporation, I had the pleasure of succeeding him as legal counsel to CORF.

In order to understand what is involved in representing the interests of radio astronomers before the FCC, one must have some knowledge of the FCC's 
procedures. The FCC's rules contain a table of allocations, which lists the radio services which are permitted to use each radio band. Radio services are usually allocated to bands on either a "primary" or "secondary" basis. A "secondary" radio service is one which cannot claim protection from harmful interference from stations of a primary service in the same band. Nor may a secondary service cause interference to a primary allocation in the same band. The FCC's Table of Allocations closely follows the International Telecommunications Union's (ITU's) Table of Allocations for Region 2 (which includes North America) but it is not identical. Such deviation is permitted under ITU rules, which allows a country to depart from the ITU Table in making domestic assignments, provided these assignments will not cause interference to stations in other countries which are operating in accordance with the ITU Table.

Amendments to FCC's table of allocations occur through what are called "rulemaking" proceedings. In order to initiate a rulemaking proceeding, a private party files a "petition for rulemaking." The FCC invites public comments and reply comments on the petition. After evaluating the comments, the FCC may, if it appears the proposal has merit, release a "Notice of Proposed Rulemaking" ("NPRM") in which it sets forth proposed rules and gives reasons why it proposes to adopt them.

Comments and reply comments on these proposed rules are invited. The FCC reviews the comments and reply to comments it receives. It then decides whether or not to adopt the rules in whole or in part. It usually expresses its opinion in a written decision called a "Memorandum Opinion and Order." The FCC's rules provide for various opportunities to seek reconsideration of and to appeal any rules which it adopts.

There are variations on this basic rulemaking procedure. For example, the FCC does not have to wait for a private entity to file a petition for rulemaking, but can issue an NPRM on its own. It can also engage in fact-gathering before it issues an NPRM by issuing a "Notice of Inquiry" first.

Changes in the use of radio frequencies which may affect radio astronomy may also occur during the application process. An entity must usually apply for a license in order to provide a radio service which has been previously established and listed in the Table of Allocations by rulemaking. Applicants to provide such service sometimes propose to operate at higher power, or with different modulation schemes, or in other ways that vary from the parameters which were contemplated when the service was established. Such changes can create significantly higher levels of interference to radio astronomers and other users of the radio spectrum. To object to an application for license, one files a "petition to deny" or, (if the objection is less serious) "comments" on the application. The FCC's rules prescribe time limits within which such an objection must be filed. The applicant has an opportunity to respond, and then the objecting party has an opportunity to reply to that response.

Advocacy for and against a rulemaking proposal or specific application is not limited to filing written comments. Parties can meet with members of the FCC to express their opinions verbally. Under the FCC's ex parte rules the fact that these meetings have occurred must sometimes be publicly announced after the meetings occur, together with a synopsis of what was said at the meeting. Many times, however, the meetings do not have to be reported.

When a rulemaking proposal or an application is identified which may affect a radio astronomy or other scientific use of a particular band, the legal 
counsel to CORF sends a copy of the document to the Secretary of CORF, Dr. Robert Riemer. Dr. Riemer circulates copies of the document to the members of CORF most concerned with the frequencies in question and CORF decides whether CORF should comment on the proposal. If comment is necessary, the legal counsel usually prepares a draft of the comments after discussing the issues with CORF members and the NSF spectrum manager. The draft comments are circulated for review among CORF members. When the members of CORF are satisfied with the draft, the comments are reviewed by members of the National Academy of Sciences (NAS). If approved, they are signed by Dr. Frank Press, the President of NAS, and are filed with the Commission.

The magnitude of the task involved in reviewing proposals coming out of the FCC should not be underestimated. The radio services which CORF seeks to protect include, in addition the radio astronomy service, the earth exploration satellite service, the space research service, the meteorological radio services, and the wildlife tracking frequencies. (For ease of reference, these are hereafter referred to as the "scientific radio services"). Both passive and active uses by these scientific radio services must be protected.

In the frequencies below $24 \mathrm{GHz}$ alone, there are fifty-nine different bands which are allocated to these different scientific radio services. Of these fifty-nine bands, twenty-eight are allocated to radio astronomy. Above $24 \mathrm{GHz}$, there are many additional bands which are allocated for scientific uses. The bands above $24 \mathrm{GHz}$, however, are not presently much used for commercial purposes. Consequently, radio astronomy operations in these bands have so far been less prone to interference than in the bands below $24 \mathrm{GHz}$.

The fifty-nine allocations to scientific radio services below $24 \mathrm{GHz}$ encompass, by my calculations, $6.94 \mathrm{GHz}$ of spectrum, or twenty-nine percent of all spectrum allocations below $24 \mathrm{GHz}$ (see Table I). Of this, $1.08 \mathrm{GHz}$ is allocated to radio astronomy on either a primary, secondary, or "admonitory" basis. By "admonitory", I mean bands in which the FCC has added footnotes containing a statement to the effect that "all practicable steps" will be taken to avoid interference to use of these bands for radio astronomy purposes. Such footnotes do not bind the FCC to protect radio astronomy, but they do represent a recognition of the importance of the band for radio astronomy. It is in these marginal allocations where some of the biggest legal battles are fought because in these bands radio astronomy does not have any guaranteed right to protection.

Nor is it only proposals for use of these fifty-nine allocations which the legal counsel of CORF needs to review. Extraband proposals must also be reviewed. Under the FCC's rules the radio astronomy service is generally protected from extraband radiation only to the extent such radiation exceeds the level permitted by the technical standards or criteria which govern the service in the band in which it operates. Proposals and applications to use adjacent bands must therefore be reviewed to see if they will cause adjacent channel interference. Proposals to use other bands must be reviewed to see whether they could result in harmonic interference to radio astronomy bands. Consequently, there are very few proposals made to the FCC which are not reviewed in at least a cursory fashion.

Aside from monitoring proposed changes to the FCC's Table of Allocations, the legal counsel to CORF must also review proposals to change the ITU regulations. 
Before every international conference, the FCC invites interested parties to submit comments concerning the position the U.S. should take at the international conference with respect to the items on the conference agenda. Frequently, the FCC will create an industry advisory committee to make recommendations. Very often, proposals are made to change the ITU allocations in ways which would affect ITU radio astronomy allocations. Typically, any such change in the ITU table is then later used by the proponents of the change as an argument for modifying the U.S. domestic allocations to bring them into line with the ITU Table of Allocations. Thus, protecting domestic radio astronomy frequencies also requires participating in preparations for international conferences. Moreover, since the U.S. delegation at international conferences has the flexibility to modify U.S. position during the course of negotiations, it is also important, if possible, to have a radio astronomy representative on the U.S. delegation or, if that is not possible, an observer present who can provide input as to the effect which any modified U.S. position will have on radio astronomy bands.

The CORF legal representation program has been successful in identifying major problems for radio astronomy as they arise at the FCC and in providing input to the FCC before it has made its initial decision on an issue. The FCC has considered these comments and in many cases has adopted CORF's position as its own. The proceeding in which the FCC established the Land Mobile Satellite Service is one recent example. There, CORF was successful in persuading the FCC to reject proposals to allow co-primary sharing of the $1660-1660.5 \mathrm{MHz}$ band by the LMSS. In the same proceeding, CORF was successful in defeating a proposal advanced by aeronautical interests to allow aeronautical public correspondence communications in this critical 500 kilohertz of spectrum. However, the battle is far from being over yet. CORF is presently examining the application filed by the Commission-mandated consortium of LMSS interests to ensure that its hard won success in the rulemaking proceeding is not subsequently lost in the application process. Moreover, the aeronautical mobile satellite service is still permitted to use the band to provide safety and regularity of flight services, although only on condition that it can protect radio astronomy use of the band. Finally, the whole question of allocations to mobile satellite services in this band may be reconsidered in 1992. CORF must begin planning its strategy for that conference now.

However, not all CORF's positions have been accepted by the FCC. It is instructive to look at a recent example to see why this has been so. In a recent NPRM, (in Docket 86-422), the FCC proposed adopting $500 \mathrm{uV} / \mathrm{m}$ (microvolts per meter) at 3 meters as the permissible level of emissions allowed for unlicensed RF radiators in bands about $1 \mathrm{GHz}$. The groups primarily affected by such regulations are manufacturers of garage door openers and security alarm devices. CORF opposed the adoption of this limit, at least as it applied to the restricted bands used by radio astronomers. Instead, it sought continued protection to a maximum of $125 \mathrm{uV} / \mathrm{m}$ at three meters in these bands, pointing out that the $500 \mathrm{uV} / \mathrm{m}$ level would vastly increase the area around a radio astronomy site within which a garage door opener could cause harmful interference. For a definition of "harmful interference," CORF relied on standards established by the CCIR.

In a decision released March 25th, FCC denied CORF's request on two 
grounds. First, it asserted that CORF's reliance on the CCIR's definition of harmful interference was misplaced, inasmuch as the CCIR assumed isotropic radio astronomy antennas when radio astronomy antennas are not isotropic. Second, the FCC said that theoretical interference calculations aside, radio astronomers had not documented any actual cases of interference. CORF has asked the FCC to reconsider its decision to set $500 \mathrm{uV} / \mathrm{m}$ at 3 meters as the Commission's limit for unlicensed RF emitters such as garage door openers, pointing out (a) that for interference purposes, radio astronomy antennas should be considered isotropic and (b) that just because no cases of interference have been documented does not mean they have not occurred.

It is possible to draw two lessons from this example. The first is the need for radio astronomers to document cases of interference when they occur. Information as to the extent of the interference, the frequency on which it occurs, its source, and the effect it has had on your ability to collect accurate data is extremely important. This is because the FCC does not protect radio as tronomy from all interference, but only harmful interference. What constitutes "harmful" interference? How much is too much? What evidence is there that interference levels are creeping upwards? These are slippery slopes where there are no clear lines of demarcation. For this reason, specific examples of problems which radio astronomers have encountered from identifiable sources are very helpful to us to prove to the FCC that the theoretical claims of harmful interference are being confirmed under field conditions.

The other lesson to be drawn from this experience has to do with educating individuals in the top levels of the FCC as to the importance of radio astronomy.

More and more frequently, there is no compromise solution satisfactory to all parties. In these cases, the FCC is required to choose between radio astronomy protection and some commercial use of the spectrum. These commercial interests are willing to spend tremendous sums to explain why interference limits should be relaxed or their service should be permitted to cause more interference in a radio astronomy band. Usually, their message boils down to the fact that the more bandwidth they are given and the fewer emission limits they must comply with, the cheaper they can provide a commercial product or service. Frequently, they express their message in doomsday terms, as in "If we are forced to spend more on filters, we will be driven out of business."

The radio astronomer's message in response to the regulations must be to convey the importance of the research which is being done using these frequencies. There is more to this than enumerating technological improvements in receiver and antenna design which have been pioneered by radio astronomers. The real value of radio astronomy, of what you are doing, can only be expressed in near-metaphysical terms about mankind's origins and ends. It must convey to the regulators at the FCC the thought which Plato expressed in The Republic in 529 B.C. when he said that "Astronomy compels the soul to look upwards and leads us from this world to another." To achieve these lofty ends, it is not unreasonable to require garage door opener manufacturers to spend an extra dollar or two on filters to protect radio astronomy from interference.

The radio engineers at the FCC are sympathetic to radio astronomers' pleas. They understand the importance of the research which is being done. But explaining to non-scientists at the top echelons of the FCC why radio astronomy cannot accept a little more interference is a process of continuous education and 
re-education.

CORF does not currently have the budget to provide this kind of on-going educational campaign at a level which fully counterbalances the educational campaigns which the commercial industries mount. This is where I feel we are falling short at present. As a result, radio astronomers have difficulty withstanding major offensives which industries launch to use spectrum in ways which increase interference to radio astronomy users.

One possible solution to this problem is to consider creating an association whose membership would be open to radio astronomers and companies which support the goals of radio astronomers and other scientific uses of the radio spectrum. Such an association would be able to raise funds through dues, trade shows, and publications. These funds could then be used to support radio astronomy positions before the FCC. In essence, such an association would be doing for radio astronomy what associations representing different commercial industries currently do for them. I recognize that many radio astronomers, who are devoted to the scientific pursuit of knowledge, will wonder why such an association is necessary. After all, you may say, the facts of interference are ascertainable by the immutable laws of physics, and if a new proposal will cause harmful interference to radio astronomy, it should not be permitted. However, policy makers at the FCC are under unrelenting pressure from commercial associations who can generate large amounts of interest from their constituents. As a consequence, unless they are exposed to the other side of the story, these policy makers are likely to conclude that there are higher and better uses for the spectrum than radio astronomy. This is a function that an association of radio astronomers could perform very effectively.

TABLE I Frequency Allocations by Type of Service

\begin{tabular}{llll}
\hline Service & Allocation & B/W (KHz) & Frequency \\
RA & Primary & $50 \mathrm{KHz}$ & $13,360-13,410 \mathrm{KHz}$ \\
RA & Primary & $120 \mathrm{KHz}$ & $25,550-25,670 \mathrm{KHz}$ \\
RA & Secondary & $500 \mathrm{KHz}$ & $37.5-38.0 \mathrm{MHz}$ \\
RA & Primary & $250 \mathrm{KHz}$ & $38.0-38.25 \mathrm{MHz}$ \\
Wildlife Tracking & Secondary & $40 \mathrm{KHz}$ & $40.66-40.70 \mathrm{MHz}$ \\
$\quad$ \& Telemetry & & & \\
RA & Primary & $1600 \mathrm{KHz}$ & $73.0-74.6 \mathrm{MHz}$ \\
Space Rsch & Secondary & $1000 \mathrm{KHz}$ & $136.0-137.0 \mathrm{MHz}$ \\
Space Rsch & Primary & $1000 \mathrm{KHz}$ & $137.0-138.0 \mathrm{MHz}$ \\
Space Rsch & Primary & $850 \mathrm{KHz}$ & $400.15-401.0 \mathrm{MHz}$ \\
Metrological Aids & Primary & & \\
Meteor. Sat. & Secondary & $1000 \mathrm{KHz}$ & $402-403 \mathrm{MHz}$ \\
Earth Expl. Sat. & Secondary & $1000 \mathrm{KHz}$ & $401-402 \mathrm{MHz}$ \\
RA & Primary & $3900 \mathrm{KHz}$ & $406.1-410.0 \mathrm{MHz}$ \\
Space Rsch & Secondary & $500 \mathrm{KHz}$ & $449.75-450.25 \mathrm{MHz}$ \\
Earth Expl. Sat. & Secondary & $10,000 \mathrm{KHz}$ & $460-470 \mathrm{MHz}$
\end{tabular}


\& Meteor. Sat. RA

$\begin{array}{lll}\begin{array}{ll}\text { Primary } \\ \text { Secondary }\end{array} & 6,000 \mathrm{KHz} & 608-614 \mathrm{MHz} \\ & 85,000 \mathrm{KHz} & 1215-1300 \mathrm{MHz} \\ \text { Admonitory } & 70,000 \mathrm{KHz} & 1300-1400 \mathrm{MHz} \\ \text { Secondary } & 30,000 \mathrm{KHz} & 1370-1400 \mathrm{MHz} \\ \text { Primary } & 27,000 \mathrm{KHz} & 1400-1427 \mathrm{MHz}\end{array}$

Earth Expl. Sat. Space Rsch

RA

Space Rsch

Earth Expl. Sat. RA

Earth Expl. Sat. Space Rsch

$R A$

RA

$R A$

Space Rach

Met. Aids

RA

RA

Space Rsch

Earth Expl. Sat.

Space Rsch

Space Rsch

Earth Expl. Sat

Space Roch

Space Rsch

Earth Expl. Sat. RA, Space Rsch

Earth Expl. Sat

Earth Exp. Sat

RA, Space Rsch

Earth Expl. Sat

Space Rsch

RA

RA

Earth Exp. Sat

Space Rsch

Space Rsch

RA

RA, Space Rsch

Earth Exp. Sat.

Space Rsch

Earth Exp. Sat.

Space Rsch

Earth Exp. Sat.

Space Rsch

Space Rsch

Earth Exp. Sat.

Space Rsch

RA

Earth Exp. Sat.

RA

\begin{tabular}{|c|c|c|}
\hline $\begin{array}{l}\text { Secondary } \\
\text { Primary } \\
\text { Primary }\end{array}$ & $\begin{array}{l}3,200 \mathrm{KHz} \\
500 \mathrm{KHz} \\
7,900 \mathrm{KHz}\end{array}$ & $\begin{array}{l}1610.6-1613.8 \mathrm{MHz} \\
1660-1660.5 \mathrm{MHz} \\
1660-1668.4 \mathrm{MHz}\end{array}$ \\
\hline Primary & $1,600 \mathrm{KHz}$ & $1668.4-1670.0 \mathrm{MHz}$ \\
\hline $\begin{array}{l}\text { Admonitory } \\
\text { Secondary }\end{array}$ & $\begin{array}{l}3,400 \mathrm{KHz} \\
85,000 \mathrm{KHz}\end{array}$ & $\begin{array}{l}1718.8-1722.2 \mathrm{MHz} \\
2025-2110 \mathrm{MHz}\end{array}$ \\
\hline $\begin{array}{l}\text { Secondary } \\
\text { Secondary }\end{array}$ & $\begin{array}{l}10,000 \mathrm{KHz} \\
90,000 \mathrm{KHz}\end{array}$ & $\begin{array}{l}2110-2120 \mathrm{MHz} \\
2200-2290 \mathrm{MHz}\end{array}$ \\
\hline $\begin{array}{l}\text { Primary } \\
\text { Secondary }\end{array}$ & $\begin{array}{l}10,000 \mathrm{KHz} \\
15,000 \mathrm{KHz}\end{array}$ & $\begin{array}{l}2290-2300 \mathrm{MHz} \\
2640-2655 \mathrm{MHz}\end{array}$ \\
\hline Secondary & $35,000 \mathrm{KHz}$ & 2655-2690 MHz \\
\hline Primary & $10,000 \mathrm{KHz}$ & $2690-2700 \mathrm{MHz}$ \\
\hline Secondary & $200,000 \mathrm{KHz}$ & $3100-3300 \mathrm{MHz}$ \\
\hline $\begin{array}{l}\text { Admonitory } \\
\text { Admonitory } \\
\text { Secondary }\end{array}$ & $\begin{array}{l}7,000 \mathrm{KHz} \\
6,700 \mathrm{KHz} \\
200,000 \mathrm{KHz}\end{array}$ & $\begin{array}{l}3332-3339 \mathrm{MHz} \\
3345.8-3352.5 \mathrm{MHz} \\
4200-4400 \mathrm{MHz}\end{array}$ \\
\hline $\begin{array}{l}\text { Secondary } \\
\text { (RA-Admonite }\end{array}$ & $\begin{array}{l}40,000 \mathrm{kHz} \\
\text { ory, only) }\end{array}$ & $4950-4990 \mathrm{MHz}$ \\
\hline $\begin{array}{l}\text { Admonitory } \\
\text { RA-Primary }\end{array}$ & $\begin{array}{ll}10,000 & \mathrm{KHz} \\
10,000 & \mathrm{KHz}\end{array}$ & $\begin{array}{l}4825-4835 \mathrm{MHz} \\
4990-5000 \mathrm{MHz}\end{array}$ \\
\hline Secondary & $10,000 \mathrm{KHz}$ & $2520-2530 \mathrm{MHz}$ \\
\hline Admonitory & & $6425-8450 \mathrm{MHz}$ \\
\hline Primary & & $8025-8400$ \\
\hline $\begin{array}{l}\text { Primary } \\
\text { Primary } \\
\text { Primary }\end{array}$ & $\begin{array}{l}50,000 \\
80,000\end{array}$ & $\begin{array}{l}7145-7190 \\
8450-8500 \mathrm{MHz} \\
10.60-10.68 \mathrm{GHz}\end{array}$ \\
\hline $\begin{array}{l}\text { (RA-primary, } \\
\text { Primary }\end{array}$ & $\begin{array}{l}\text { footnote) } \\
20,000\end{array}$ & $10.68-10.70 \mathrm{GHz}$ \\
\hline
\end{tabular}

Space Rsch 


\begin{tabular}{|c|c|c|c|c|}
\hline Space & Rsch & Secondary & 500,000 & $12.75-13.25 \mathrm{GHz}$ \\
\hline space & Rsch & Secondary & 150,000 & $13.25-13.40 \mathrm{GHz}$ \\
\hline space & Rsch & Secondary & 600,000 & $13.4-14.0 \mathrm{GHz}$ \\
\hline space & Rsch & Secondary & 200,000 & $14.0-14.2 \mathrm{GHz}$ \\
\hline RA & & Admonitory & 30,000 & $14.47-14.5 \mathrm{GHz}$ \\
\hline $\begin{array}{l}\text { Space } \\
\text { Earth }\end{array}$ & $\begin{array}{l}\text { Rsch } \\
\text { Exp. Sat. }\end{array}$ & Secondary & 150,000 & $15 \cdot 20-15 \cdot 35 \mathrm{GHz}$ \\
\hline $\begin{array}{l}\text { Earth } \\
\text { RA }\end{array}$ & Expl. & Primary & 50,000 & $15.35-15.40 \mathrm{GHz}$ \\
\hline space & Rsch & & & \\
\hline $\begin{array}{l}\text { Earth } \\
\text { space }\end{array}$ & $\begin{array}{l}\text { Expl. Sat. } \\
\text { Rsch }\end{array}$ & Secondary & 100,000 & $17.2-17.3 \mathrm{GHz}$ \\
\hline $\begin{array}{l}\text { Earth } \\
\text { space }\end{array}$ & $\begin{array}{l}\text { Exp. Sat. } \\
\text { Rsch }\end{array}$ & Primary & 200,000 & $18.6-18.8 \mathrm{GHz}$ \\
\hline $\begin{array}{l}\text { Earth } \\
\text { Space }\end{array}$ & $\begin{array}{l}\text { Exp. Sat. } \\
\text { Rsch }\end{array}$ & Secondary & 200,000 & $21.2-21.4 \mathrm{GHz}$ \\
\hline $\begin{array}{l}\text { Earth } \\
\text { Space }\end{array}$ & $\begin{array}{l}\text { Exp. Sat. } \\
\text { Rsch }\end{array}$ & Primary & 600,000 & $21.4-22.0 \mathrm{GHz}$ \\
\hline RA & & Admonitory & 200,000 & $22.1-22.21 \mathrm{GHz}$ \\
\hline $\begin{array}{l}\text { Earth } \\
\text { Space }\end{array}$ & $\begin{array}{l}\text { Exp. Sat. } \\
\text { Rsch }\end{array}$ & $\begin{array}{l}\text { Secondary } \\
\text { (RA-primary }\end{array}$ & 290,000 & $22.1-22.50 \mathrm{GHz}$ \\
\hline RA & & Admonitory & 50,000 & $22.81-22.86 \mathrm{GHz}$ \\
\hline RA & & Admonitory & 50,000 & $23.07-23.12 \mathrm{GHz}$ \\
\hline $\begin{array}{l}\text { Earth } \\
\text { RA }\end{array}$ & Exp. Sat. & Primary & 400,000 & $23.6-24.0 \mathrm{GHz}$ \\
\hline
\end{tabular}

